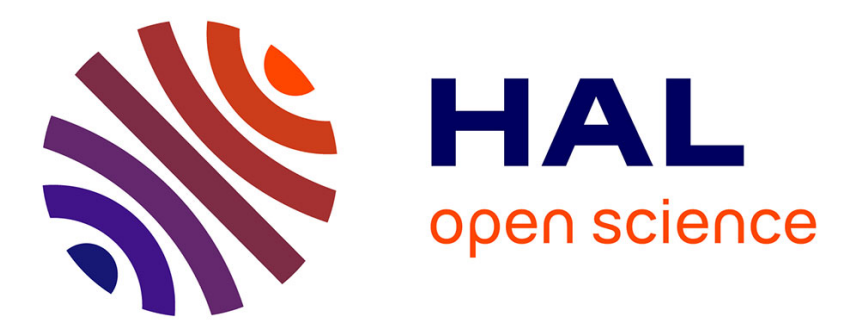

\title{
An optimization approach of computer generated hologram (CGH) for divergent light shaping
}

Qiang Song, Yoran Eli Pigeon, Xavier Theillier, Kevin Heggarty

\section{To cite this version:}

Qiang Song, Yoran Eli Pigeon, Xavier Theillier, Kevin Heggarty. An optimization approach of computer generated hologram $(\mathrm{CGH})$ for divergent light shaping. Digital Holography and ThreeDimensional Imaging, 2019, Bordeaux, France. pp.Tu4A.5, 10.1364/DH.2019.Tu4A.5 hal-02189546

\section{HAL Id: hal-02189546 \\ https://imt-atlantique.hal.science/hal-02189546}

Submitted on 19 Jul 2019

HAL is a multi-disciplinary open access archive for the deposit and dissemination of scientific research documents, whether they are published or not. The documents may come from teaching and research institutions in France or abroad, or from public or private research centers.
L'archive ouverte pluridisciplinaire HAL, est destinée au dépôt et à la diffusion de documents scientifiques de niveau recherche, publiés ou non, émanant des établissements d'enseignement et de recherche français ou étrangers, des laboratoires publics ou privés. 


\title{
An optimization approach of computer generated hologram (CGH) for divergent light shaping
}

\author{
Qiang Song, Yoran Eli Pigeon, Xavier Theillier, Kevin Heggarty \\ IMT Atlantique, OPT Department, Technopôle Brest-Iroise CS83818, 29238 Brest, France \\ e-mail: qiang.song@imt-atlantique.fr
}

\begin{abstract}
An optimization method of pure phase CGH for beam shaping with divergent incoherent light is proposed. The sample experiment fabricated with our home built photo-plotter shows a good agreement with the numerical simulation results.
\end{abstract}

OCIS codes: $090.2870,140.3300,090.1760$

\section{Introduction}

The researches of divergent light illumination are mainly concentrated in refractive or reflective optical element (ROE) for a long time [1-2]. Although these ROE based method can get an asymmetric pattern with a freeform lens or facet surface structure, the large scale size and thickness limit their applications. Computer generated hologram $(\mathrm{CGH})$ is a good choice to solve this problem up to now. However, there is rarely research work relevant with the CGH design illuminated by divergent incoherent light. Here in this paper, the strategy of divergent source model, complex degree of coherence and a modified magnitude constraint are introduced into the standard iterative Fourier transform algorithm(IFTA) process[3]. With this proposed method, a good performance for incoherent light shaping is obtained.

\section{Methodology and Results}

The classical IFTA is one of the most popular algorithms, which has been widely used in phase retrieval problem and calculation of CGHs. Numerically, the IFTA is a forward and inverse Fourier transformation process of a complex function between the real(object) space and Fourier(image) space, in which the constraints are applied to the computed wave-front by a prior knowledge. Generally the standard IFTA is valid only in paraxial region and often used for plane wave shaping. So the model should be modified when the divergent light source is used.

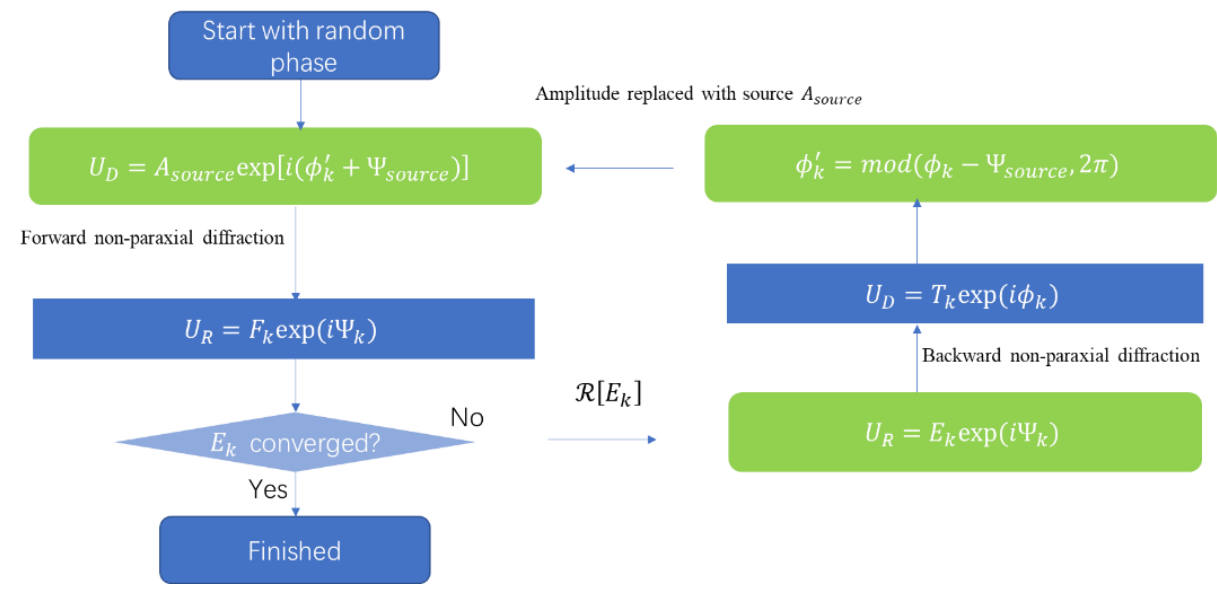

Fig.1. Flow chart of the proposed optimization method.

The proposed strategy is to use the scalar non-paraxial diffraction formula as the propagating function between two domains[4], and introduce the divergent light source model in the object space and the modified constraint in the Fourier space, as shown in Fig.1. The constraint in the $k$ th iteration is implemented by modifying $\left|E_{k}\right|$ in the way as 


$$
\begin{gathered}
\mathcal{R}\left[E_{k}\right]=\left\{\begin{array}{cc}
\varepsilon_{k}\left[\mu_{k}\left(\omega_{1} E_{\text {target }}-\omega_{2} E_{k}\right)\right] & \Omega \in \text { signal window } \\
E_{k} & \Omega \notin \text { signal window }
\end{array}\right. \\
\varepsilon_{k}=\frac{\sum_{\Omega_{S}} E_{\text {target }}}{\sum_{\Omega_{S}} E_{k}} \\
\mathcal{R}\left[\mu_{k}\right]=\frac{E_{\text {target }}}{E_{k}} \mu_{k}
\end{gathered}
$$

In eq.(1), the subscript $k$ indicates the number of iteration, $E_{\text {target }}$ is the target amplitude in Fourier domain, $\omega_{1}$ and $\omega_{2}$ are empirical parameters. A binary image ' $\pi$ ' is used to demonstrate the proposed algorithm. In this design, the distance between LED source and CGH is 50mm, and the effective area of the $\mathrm{CGH}$ is $12 \mathrm{~mm} \times 12 \mathrm{~mm}$ with pixel size $0.75 \mu \mathrm{m}$, the collective divergent angle is $14^{\circ}$ The fabricated phase levels are quantized, so the surface relief of the CGH should be divided into several levels. In theory, the higher the number of phase levels, the better the reconstructed image quality. However, the fabrication performance must also be considered. Empirically, eight levels is a good practical compromise. The optimized CGH was fabricated with our home-built photo-plotter [5], which has $16000 \times 16000$ pixels. When the fabricated CGH is illuminated by using a divergent LED (wavelength 525nm), see Fig.2 (b). The replayed image is shown in Fig. 2(c). The experimental reconstructed result shows a good agreement with the simulation result (Fig.2(a)). From Fig.2 (c), the signal to noise ratio (SNR) of the reconstructed image is high enough, and the zero order diffraction spot is rarely observed using the $\mathrm{CGH}$ optimized by our proposed algorithm
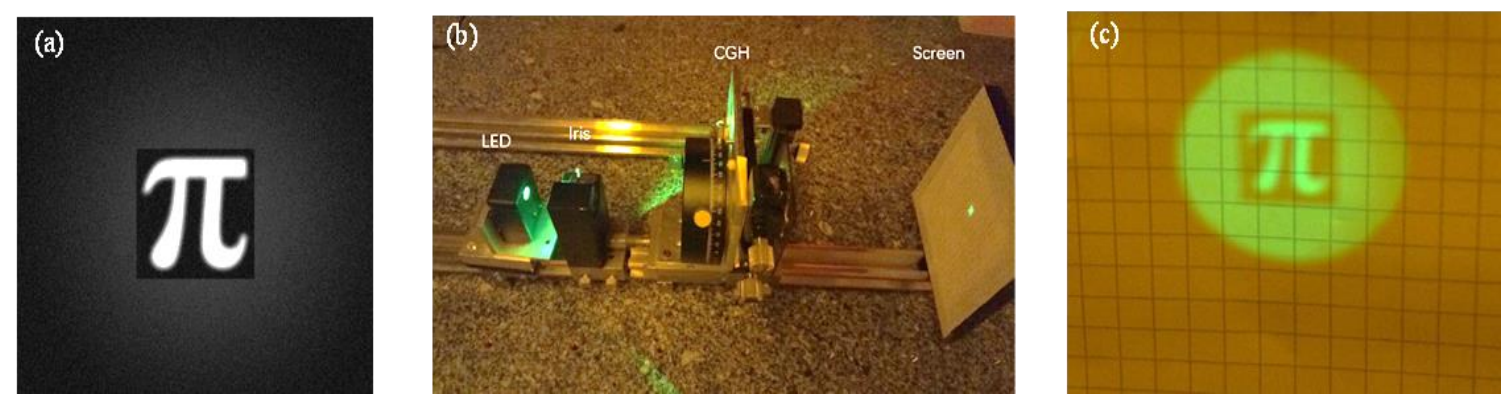

Fig.2. (a) Simulation result (b) Experiment setup (c) Intensity distribution on the screen as a result of illuminating the $\mathrm{CGH}$ with a green LED source.

\section{Conclusion}

In this work, the modified IFTA method is proposed by introducing the strategy of divergent light source model and scaler non-paraxial diffraction model. The optical experiment result shows high relevance to the numerical simulation result, which demonstrates that the proposed method has good performance in divergent light shaping. The proposed design method can also find applications in diffractive optical elements design for anti-counterfeiting protecting, as well as computational imaging.

\section{References}

[1] Vladimir Oliker, “ Optical design of freeform two-mirror beam-shaping systems,” J. Opt. Soc. Am. 24(12), 3741-3752(2007).

[2] Weitao Song, Dewen Cheng, Yue Liu, and Yongtian Wang, “ Free-form illumination of a refractive surface using multiple-faceted refractors,” Appl. Opt. 54(28), E1-E7(2015).

[3] Frank Wyrowski, "Diffractive optical elements: iterative calculation of quantized, blazed phase structures,” J. Opt. Soc. Am. 7(6), 961-969(1990).

[4] G.-N. Nguyen, K. Heggarty, A. Bacher, P.-J. Jakobs, D. Häringer, P. Gérard, et al., Iterative scalar nonparaxial algorithm for the design of Fourier phase elements, Opt. Lett. 39 (2014) 5551-5554

[5] M.V.Kessels, C.Nasour,P.Grosso, K.Heggarty, “ Direct write of optical diffractive elements and planar waveguides with a digital micromirror device based UV photoplotter," Opt.Comm.283(15), 3089-3094(2010). 